\title{
Comentário
}

\section{O IMS e os desafios de hoje}

| ${ }^{1}$ Gulnar Azevedo e Silva, ${ }^{2}$ Rossano Cabral Lima |

${ }^{1}$ Instituto de Medicina Social, Universidade do Estado do Rio de Janeiro. Rio de Janeiro-RJ, Brasil (gulnar@ims.uerj.br).

${ }^{2}$ Instituto de Medicina Social, Universidade do Estado do Rio de Janeiro. Rio de Janeiro-RJ, Brasil (rossanolima1@gmail.com).

O Instituto de Medicina Social (IMS), desde sua origem, no início da década de 1970, sempre priorizou a formação em pós-graduação e as pesquisas sobre a saúde das populações e áreas correlatas.

O nome "Medicina Social", dado no momento de sua criação, já se distinguia do título "Higiene", utilizado na época na Universidade Estado do Rio de Janeiro (UERJ) e, também, de "Saúde Pública", termo que no Brasil ficou reconhecido e identificado pelas ações realizadas pela Fundação Especial de Saúde Pública (Fundação SESP). A concepção de Medicina Social era mais ampla porque associava ciências sociais, epidemiologia (priorizando a determinação social das doenças) e políticas de saúde. Incluía, ainda, correntes do planejamento e administração de saúde e contemplava os fatores biopsicossociais implicados nos fenômenos da saúde e da patologia (CORDEIRO, 2004).

Assim, o IMS, ao mesmo tempo que se voltava para questôes referentes à organização do sistema de saúde, também dirigia seu olhar para o indivíduo e sua subjetividade. Nossos professores participaram ativamente do movimento sanitário dos anos 1980, que levou à construção da proposta de unificação dos serviços de saúde, dando origem ao SUS (CORDEIRO, 2004). Isto, no entanto, se deu mantendo o equilíbrio entre o social e o individual, o que pode ser visto nas diversas linhas de pesquisa do Instituto, desde a saúde mental - a partir dos estudos iniciados nos anos 1970 pelos professores Jurandir Freire Costa e Joel Birman, hoje aposentados - até as investigaçōes sobre gênero e sexualidade tendo em Maria Andréia Loyola, hoje também aposentada, uma das pioneiras. Em 
artigo intitulado "A antropologia da sexualidade no Brasil", publicado na Physis, Loyola discorre sobre a realização em 1983, no IMS, do Primeiro Seminário do Grupo de Trabalho Sexualidade e Reprodução da ABEP (Associação Brasileira de Estudos Populacionais), e aponta questóes ainda atuais para todo o IMS, que tem na interdisciplinaridade uma marca fundamental: "[...] fazer face, ao mesmo tempo, a um vazio conceitual e à diversidade de temas e marcos teóricos que povoam esses espaços fronteiriços entre as ciências parecia, desde então, um dos principais desafios para o estudo da sexualidade (LOYOLA, 2000, p. 146).

O IMS cresceu nestes seus mais de 50 anos de existência. Nosso programa de pós-graduação, criado em 1974 com o título de "Medicina Social”, e que em 1987 foi renomeado de "Saúde Coletiva", já formou inúmeros alunos que puderam nuclear a produção de conhecimento em outros locais a partir da formação aqui recebida, possibilitando a criação de outros cursos em várias instituições no país.

Hoje somos 48 professores ativos distribuídos entre os três departamentos existentes: (i) Planejamento e Administração em Saúde, (ii) Políticas e Instituições de Saúde e (iii) Epidemiologia. Em 2015, entre mestrandos e doutorandos, foram 180 alunos matriculados; 176 alunos concluíram os cursos de especialização nas áreas de Ensino e Saúde, Gênero e Sexualidade, Gestão em Saúde e Medicina do Trabalho. Contamos com 60 grupos de pesquisa que se distribuem entre as 18 linhas em desenvolvimento. Além disto, as 40 parcerias com instituiçôes de outros países têm fortalecido o caráter internacional de nosso trabalho. Nosso programa de pós-graduação atingiu, em 2012, a nota máxima (7) pela avaliação da CAPES, o que indica que crescemos com qualidade segundo avaliação de nossos pares.

Não é, contudo, sem dificuldades e tensões que essa trajetória vem acontecendo; mas, sem dúvida, o vínculo com a saúde coletiva nunca foi perdido. Este talvez seja o maior capital acumulado ao longo desses anos: o compromisso inegável com a melhoria das condições de saúde da população brasileira.

Para dar continuidade e ampliar este compromisso, sem abrir mão da qualidade de nosso trabalho, incentivamos o convívio e a maior integração entre os três departamentos do IMS que se unem no Programa de Pós-Graduação em Saúde Coletiva, no qual estão inseridas linhas de pesquisa que indicam a complexidade e as necessidades de investigação em saúde hoje. Desta forma, 
o desafio da interdisciplinaridade continua a ser enfrentado diariamente pelos professores e alunos do IMS na abordagem de problemas contemporâneos como direitos reprodutivos, determinantes sociais e ambientais da saúde e da doença, violências e seus efeitos, doenças emergentes e negligenciadas, envelhecimento, medicalização, reforma psiquiátrica, saúde global, impacto social e subjetivo de novos diagnósticos e tecnologias de saúde, integralidade nos cuidados, avaliação do complexo médico-industrial, modelagens complexas para compreensão de processos saúde-doença, uso de grandes bancos de dados em saúde, entre outros.

Neste momento, mais uma vez, passamos por momentos difíceis no país, em nosso estado e em nossa universidade, especialmente no que diz respeito às políticas de saúde, de incentivo à pesquisa e à educação. Enfrentando esta dura conjuntura, persistiremos trabalhando pela saúde coletiva em todas as suas dimensões e em defesa do Sistema Único de Saúde. Daremos continuidade aos nossos objetivos, bem definidos por Bezerra e Sayd (1993) como de "dupla vocação": oferecer aos alunos a formação teórica e a crítica política. Concordamos com a afirmação de Hésio Cordeiro (2004, p. 359): "Teoria e prática implicam novas questôes. A utopia do SUS e da equidade são postas a cada momento, desafiadoramente". É nosso dever manter e ampliar este alvo.

Diante deste quadro atual, é necessário reforçar uma agenda estratégica que dê continuidade à nossa trajetória unindo pesquisa e crítica, ao mesmo tempo em que favoreça a persistência do olhar no coletivo e no indivíduo. Devemos continuar fortalecendo a interlocução com entidades e associações de Saúde Coletiva nacionais e internacionais, assim como as parcerias técnico-científicas com outras instituições de pesquisa no país e no exterior.

O espaço livre e democrático conquistado com tanta luta, resistência e, sobretudo, criatividade, deve trazer para o debate as grandes questôes da sociedade e da política de saúde, incluindo também os alunos egressos e professores eméritos. Neste momento de enfrentamento de adversidades no campo político e sanitário, no Brasil e no estado do Rio de Janeiro, é preciso defender as conquistas sociais das últimas décadas, criar condições para avanços futuros e, principalmente, garantir a permanência do diálogo entre os diversos atores que compóem a comunidade do IMS e todos os seus interlocutores externos. 
BEZERRA JR, B.; SAYD, J.D. Um mestrado certo para um momento preciso. Rio de Janeiro: IMS-UERJ, 1993 (Série Estudos em Saúde Coletiva).

CORDEIRO, H. O Instituto de Medicina Social e a luta pela reforma sanitária: contribuição à história do SUS. Physis: Revista de Saúde Coletiva. Rio de Janeiro, v. 14, n. 2, p. 343-362, 2004.

LOYOLA, M. A. A antropologia da sexualidade no Brasil. Physis: Revista de Saúde Coletiva. Rio de Janeiro, v. 10, n. 1, p. 143-167, 2000. 